\title{
Repertorios interpretativos del comerciante informal venezolano en la red social Twitter
}

\section{Interpretative repertoires of the Venezuelan informal trader on the social network Twitter}

\author{
Edgar Mauro Yalta Gonzales ${ }^{1}$ \\ Universidad Nacional Mayor de San Marcos. Lima, Perú \\ edgar.yalta@unmsm.edu.pe \\ ORCID: https://orcid.org/0000-0001-8444-6779
}

Mirella Alexandra Robles Muñoz ${ }^{2}$

Universidad Nacional Mayor de San Marcos. Lima, Perú

mirella.robles@unmsm.edu.pe

ORCID: https://orcid.org/0000-0002-9812-1606

\author{
Marco Antonio Lovón Cueva ${ }^{3}$ \\ Universidad Nacional Mayor de San Marcos. Lima, Perú \\ mlovonc@unmsm.edu.pe \\ https://orcid.org/0000-0002-9182-6072
}

Citar como: Yalta, E., Robles, M. y Lovón, M. (2021). Repertorios interpretativos del comerciante informal venezolano en la red social Twitter. Desde el Sur, 13(3), e0034

\section{RESUMEN \\ La migración venezolana en Latinoamérica es con- siderada el fenómeno migratorio más importante de los últimos años y el Perú no ha sido ajeno a este fenómeno.}

1 Estudiante del décimo ciclo de Lingüística de la Universidad Nacional Mayor de San Marcos (UNMSM). Pertenece al grupo de investigación Lenguas y Filosofías del Perú (LFP) de la Facultad de Letras y Ciencias Humanas de la UNMSM. Sus principales campos de interés son el análisis del discurso, la sociolingüística, la etnolingüística y la antropología. Ha publicado artículos de investigación en revistas nacionales, y ha participado como expositor en encuentros y conferencias nacionales e internacionales.

2 Estudiante del décimo ciclo de Lingüística de la UNMSM. Sus campos de interés son la sociolingüística, la lexicografía y el análisis del discurso. Ha colaborado en publicaciones para las revistas Lengua y Sociedad y Tierra Nuestra. Asimismo, ha participado como expositora en Expoletras IX-2019, en el Encuentro de Jóvenes Investigadores en Humanidades, durante dos años consecutivos, 2020 y 2021, y en el XXII Diálogo de Estudiantes de Lingüística 2021. 3 Doctor y magíster en Lingüística por la Pontificia Universidad Católica del Perú (PUCP). Licenciado y bachiller en Lingüística por la UNMSM. Enseña cursos de Lingüística Aplicada, Seminario de Investigación Avanzada en temas de Lingüística Migratoria y Seminario de Tesis. Cuenta con estudios de posgrado por la Escuela de Lexicografía Hispánica (ELH) de la Real Academia Española (RAE) y bachillerato en Ciencia Política por la UNMSM. Es asesor de tesis multidisciplinarias, y forma parte de los grupos de investigación Lenguas y Filosofías del Perú (LFP) y Lexi. Es profesor investigador Concytec en la categoría Carlos Monge III. Dicta cursos en la maestría de Lingüística en la UNMSM y es expositor en conferencias nacionales e internacionales. 
La comunidad venezolana en el Perú suele ser víctima de procesos xenófobos y racistas por motivos vinculados con la informalidad y el uso de los espacios públicos. El rechazo frecuentemente se evidencia en los medios de comunicación, especialmente por los usuarios en las redes sociales. El presente artículo tiene como objetivo analizar, desde el enfoque de la psicología discursiva, los repertorios interpretativos que se construyeron para expresar discursivamente el rechazo por parte de los usuarios peruanos hacia el comerciante informal venezolano en la red social Twitter. Para ello, seleccionamos un conjunto de tuits representativos que explicitan este rechazo hacia los comerciantes informales venezolanos. Los resultados evidencian el uso de tres principales repertorios interpretativos: invasores de los espacios públicos, criminalización y el nacionalismo-pertenencia.

\section{PALABRAS CLAVES}

Psicología discursiva, repertorios interpretativos, Twitter, comercio informal, migración venezolana

\section{ABSTRACT}

Venezuelan migration within Latin America is considered the most significant migratory phenomenon in recent years and Peru has not been unaffected by this phenomenon. The Venezuelan community in Peru is often the victim of xenophobic and racist processes motivated by associations with the informal sector and the use of public spaces. Rejection is frequently expressed across different types of media, particularly by users of social networks. The aim of this article is to analyze, from a discursive psychological approach, the interpretative repertoires constructed in order to discursively express the rejection by Peruvian users aimed at Venezuelan informal traders via the social network Twitter. To this end, we selected a set of representative tweets in which such rejection of Venezuelan informal traders is made explicit. The results indicate the use of three main interpretative repertoires: invaders of public spaces, criminalization and nationalism-belonging.

\section{KEYWORDS}

Discursive psychology, interpretative repertoires, Twitter, informal trading, Venezuelan migration 


\section{Introducción}

La migración venezolana en Latinoamérica es considerada uno de los fenómenos migratorios más importantes (Blouin, 2019). Según los datos proporcionados por el Alto Comisionado de las Naciones Unidas para los Refugiados (Acnur, 2019), Colombia, Perú y Chile fueron los países que recibieron mayor cantidad de migrantes venezolanos (506 000 en el Perú). En el caso peruano, Loayza (2020) señala que «durante el año 2017 se produjo un intenso proceso migratorio» (p. 180) que trajo como consecuencias la explotación en el ámbito laboral, la xenofobia hacia los migrantes y la trata de personas. En el aspecto laboral, Berganza y Solórzano (2019) agregan que en el Perú los migrantes venezolanos se han visto obligados a integrarse dentro del mercado laboral de manera informal a causa de las dificultades encontradas para desempeñarse en un trabajo formal; además, añaden que las dificultades se relacionan con el problema de los reconocimientos de títulos universitarios y la falta de recursos. Esto se refleja también en que «hasta abril del 2018 , solo el $4,9 \%$ de venezolanos tenía un trabajo formal, mientras que el $95,1 \%$ se encontraba laborando de manera informal» (Berganza y Solórzano, 2019, p. 93).

Ahora bien, la inserción laboral de los migrantes venezolanos se dificulta ante a la xenofobia generada por los prejuicios y el racismo de parte de los peruanos. Bruno y Arrúa (2019) señalan que los migrantes venezolanos en el Perú «encontraron resistencia por parte de la sociedad local para contratarles o alquilarles un lugar para residir» (p. 298) y experimentan situaciones de rechazo por su nacionalidad. Loayza (2020) agrega que este rechazo hacia los migrantes venezolanos en el Perú se evidencia especialmente en Lima, lugar donde son tratados de peor manera. Estos actos de xenofobia y rechazo se reflejan en los hechos acontecidos en los últimos años en Lima. Por ejemplo, los casos más significativos son los constantes enfrentamientos entre los comerciantes informales venezolanos contra los fiscalizadores municipales o los propios comerciantes informales peruanos. Estos eventos ocurren recurrentemente en el emporio comercial de Gamarra en el distrito de La Victoria, en los mercados mayoristas del Centro de Lima o en los mercados de los distritos periféricos ( $E I$ Comercio, 2019a; Trome, 2019; La República, 2020).

Ante estos enfrentamientos, se generan reacciones polarizadas respecto a la situación del comerciante informal venezolano en los medios de comunicación e, incluso, la problemática se expande hacia el ámbito político. Por ejemplo, los ambulantes y el migrante venezolano, en las elecciones de los últimos años, tanto congresales extraordinarias como presidencial, han sido objeto de las promesas políticas en torno al uso de los espacios públicos y en el aspecto laboral del país. En el caso de los 
medios de comunicación — diarios, televisión, radio y redes socialeslas reacciones y percepciones hacia los comerciantes informales venezolanos, y migrantes en general, se alimentaron de una carga xenófoba y racista; en consecuencia, se generó una imagen de rechazo hacia ellos sostenida por los prejuicios previamente señalados. En el caso de las redes sociales, este rechazo se explicita a través de la elaboración de discursos (comentarios, tuits, etc.) por parte de los usuarios. Para esta investigación, nos enfocamos en los discursos que elaboraron (a través de sus tuits) los usuarios peruanos de la red social Twitter. Además, aplicamos el análisis de los repertorios interpretativos - concepto que pertenece al enfoque de la psicología discursiva (Potter y Wetherell, 1987; Wetherell y Potter, 1996) - , ya que nos permite observar las posturas y las versiones de la realidad de los individuos que expresan por medio del lenguaje.

En síntesis, en el presente artículo nos planteamos como objetivo analizar, desde el enfoque de la psicología discursiva, los repertorios interpretativos que se construyeron para expresar discursivamente el rechazo por parte de los usuarios peruanos hacia el comerciante informal venezolano en la red social Twitter. Consideramos que la investigación permite conocer la percepción de los usuarios peruanos en las redes sociales hacia los migrantes venezolanos y observar las representaciones que se originan debido a la influencia de procesos xenófobos, el racismo y el rechazo. Por último, destacamos y evidenciamos la interdisciplinariedad de los estudios discursivos para trabajar con otras disciplinas como la psicología social y las ciencias económicas.

\section{Marco conceptual}

\section{Repertorios interpretativos}

El análisis de discurso (AD) posibilita comprender las prácticas discursivas de las personas que se generan dentro de su vida social y en las que el uso del lenguaje es parte. El AD ha ido estudiando desde diversas perspectivas el uso que hacen del lenguaje las personas, como lo hace la psicología discursiva. A esta, por ejemplo, le interesa el papel que juega el lenguaje en la definición de las categorías psicológicas en interacción, así como la misma actuación de los participantes para dar respuestas adaptativas a las diversas situaciones a través del uso del lenguaje (Fernández, 2009 , p. 72). Dentro de la psicología discursiva destaca el análisis de repertorios interpretativos que dan cuenta de líneas argumentativas coherentes que hacen uso de recursos lingüísticos durante las interacciones. El repertorio interpretativo es una categoría conceptual teórica y analítica desarrollado por psicólogos sociales, como Jonathan Potter y Margaret Wetherell, que sostiene que con el lenguaje se construyen versiones del 
mundo social. Y que a través de su identificación y análisis se pueden conocer los relatos de las personas. Este concepto que permite el análisis de los discursos sirve también como un lente de interpretación no solo para los analistas del discurso desde la psicología, sino también para los lingüistas, quienes por medio de la investigación de las piezas y fenómenos lingüísticos hacen ver que el lenguaje no es neutral, sino que hay maneras de usarlo y seleccionarlo. Para algunos investigadores, el análisis de repertorios podría tomarse como una técnica de análisis de información cualitativa; sin embargo, en este trabajo se parte por enmarcar el concepto y desarrollar la descripción y análisis a partir de él.

Los repertorios son ideales que los hablantes emplean para construir sus acciones, sus procesos cognitivos y otros fenómenos. Estos se constituyen por un conjunto de términos que derivan de una o más metáforas u otras figuras retóricas (Wetherell y Potter, 1992), léxico, campos semánticos, frases (Zavala, 2016). Para Wetherell y Potter (1992, p. 90), los repertorios interpretativos agrupan términos, descripciones y figuras discursivas que se ensamblan a partir de metáforas o imágenes vívidas a partir de experiencias personales y se emplean para dar sentido a la experiencia. Según Fuentes (2015), son bloques semánticos que se utilizan como constitutivos de la experiencia. Es decir, se tratan de narraciones que viabilizan información que procede de la personal y social. En este sentido, la vida cotidiana y el lenguaje son lugares donde opera la subjetividad y en esa interacción los actores sociales generan repertorios interpretativos (Fuentes, 2015). Potter y Wetherell (1987) señalan que la caracterización y evaluación de acciones y eventos de un repertorio interpretativo se realiza por medio del léxico o el registro de términos y el uso de metáforas. Para ellos, se trata de recursos empleados de forma recurrente (p. 149).

Dichos repertorios, asimismo, están determinados por factores históricos, sociales y culturales (Bassaletti-Contreras, 2013, p. 10). Según Zavala (2016, p. 211), la gente habla o piensa sobre cosas y eventos valiéndose de repertorios interpretativos que han sido construidos por medio de la historia, y los cuales también terminan por influir sobre lo que la gente hace y dice. Además, muestran discursos implícitos que reflejan actitudes y opiniones (Briones-Vozmediano et al., 2016, p. 328). Por eso, las producciones discursivas están construidas históricamente a partir de un ensamblaje de repertorios que actúan como una matriz de inteligibilidad semántica, y que son legitimados y situados por la acción social (Calquín, 2020, p. 211).

Con el análisis de los repertorios se puede descubrir que a través del uso de partículas gramaticales de impersonalidad se proyecta una imagen de neutralidad que construye un grupo de hablantes. Potter y Wetherell (1987) sostienen que los repertorios interpretativos son usados para 
otorgar explicaciones, por lo que están disponibles para la gente; es decir, no se encuentran intrínsecamente ligados a un específico grupo social. Para Mesía (2014), se tratan de recursos culturales compartidos (p. 17), pues proporcionan la base para el entendimiento social compartido y parten del sentido común, y se conectan con las posiciones o posturas de los sujetos, de manera temporal o permanente (Edley, 2001), y traen efectos prácticos para personas y grupos. Para Sánchez (2015), los repertorios traen consecuencias ideológicas. Los individuos pueden adoptar una posición en que construye una identidad xenofóbica de la migración o, por el contrario, una de tolerancia antirracista. Dichos repertorios, sobre todo los dominantes, traslucen ideologías, como la masculinidad, la existencia de una lengua culta o el racismo. Los repertorios interpretativos posibilitan la justificación de versiones particulares de eventos, la validación de comportamientos y la mantención de una postura creíble en una interacción (Burr, 1995, pp. 126-127, citado en Mesía, p. 18). A través de ello se pueden justificar y construir explicaciones racistas (Wetherell y Potter, 1996) y también contrarias (Wetherell, 1998). Un repertorio puede ofrecer argumentos a favor de aceptar o rechazar un objeto. Así se puede generar argumentos para permanecer en el hogar a edades avanzadas. Para ello se asocia un conjunto de atributos favorables al hogar (Aceros, Cavalcante, Domènech, 2018), mientras que otros soportan ideas contrarias.

Finalmente, cabe señalar que en términos de investigación los repertorios interpretativos, a pesar de la variabilidad, se obtienen de los patrones o las pautas regulares que las personas mantienen en el discurso. La información se categoriza en torno a los repertorios que dan sentido a la vida social de los individuos.

\section{Comercio informal}

Respecto al comercio y sector informal, De Soto (1989) señala que es el conjunto de empresas, trabajadores y actividades que operan fuera del marco legal y reglamentario; de esta manera, se entiende que pertenecer al sector informal significa mantenerse al margen de los impuestos y las normas legales, pero no cuenta con protección y servicios que brinda el Estado. Respecto al sector informal en América Latina, Quispe et al. (2018) indican que representa aproximadamente más del $50 \%$ de la población económicamente activa (PEA) y ocupan ampliamente las calles de las ciudades del continente. De esta manera, la presencia de los comerciantes informales «vienen transformando los espacios públicos en mercados populares de gran magnitud» (Quispe et al., 2018, p. 4). Por esta razón, el estudio del sector informal y sus actores se ha convertido en un aspecto altamente investigado en los países de Latinoamérica; por ejemplo, los 
estudios sobre las causas de su aparición y las consecuencias que generan en la economía de los países y sus ciudades (Loayza, 2007; Bustamante et al., 2009; Camargo, 2014; Cruz, 2015; Chicaiza, 2017).

Respecto a las principales causas de la aparición del comercio informal, Quispe et al. (2018) señalan que están relacionadas con los procesos migratorios, el desconocimiento de las normas tributarias, el crecimiento poblacional y la falta de regulación de los espacios públicos. Además, los autores agregan que son relevantes los siguientes factores: la edad, el nivel de instrucción, los ingresos y la estabilidad laboral. En el caso del comercio informal en el Perú, Loayza (2007) indica que es un fenómeno complejo y multifacético; asimismo, tomando en consideración mediciones, añade que el Perú evidencia niveles alarmantes de informalidad y representa uno de los más altos en el mundo. En esta línea, es importante señalar que las actividades más desarrolladas de comercio informal suelen ser la venta ambulatoria de alimentos o prendas de vestir. Por otro lado, a partir de la migración venezolana, la informalidad en el Perú se ha visto en aumento y esto no solo se explicita en Lima Metropolitana (Nolazco et al., 2020), sino también en otras ciudades del Perú (Condori et al., 2020).

\section{Migración venezolana}

La migración es un proceso variable, en la medida en que se efectúa por distintos motivos, que actualmente se encuentra muy presente en países de Latinoamérica. Se trata del desplazamiento de personas de un territorio a otro, con la finalidad de satisfacer necesidades. Gómez (2010) distingue dos tipos de migración: la emigración o salida de personas y la inmigración o entrada de personas; asimismo, el autor señala que el traslado de personas puede darse al interior de un mismo país o hacia el exterior, ya sea de manera voluntaria o forzosa. Así, en el marco de una migración internacional, se reconocen causas y efectos que influyen, tanto al país de origen como al país de destino. Entre las principales causas y efectos que señalan los autores (Aruj, 2008; Gómez, 2010; Núñez, 2008) se identifican los relacionados con las variables socioeconómicas; por ejemplo, las altas tasas de desempleo en el país de origen hacen que las personas se desplacen, con la finalidad de trabajar, hacia países que tienen mayores posibilidades de subsistencia (para ellos y sus familiares).

En los últimos años, el Perú se ha convertido en país de destino de una gran cantidad de migrantes venezolanos. Aproximadamente, solo hasta 2019, el Perú acogía a 506000 migrantes venezolanos (Acnur, 2019). La causa de este desplazamiento se debe a la vulneración de los derechos fundamentales que se evidencia en el país de Venezuela y que se traslada a los sectores político, social y económico (Blouin, 2017; Koechlin, 2018). 
La migración forzada que ocurre es porque el Estado venezolano no garantiza ni los modos de vida ni la seguridad y dignidad de las personas, lo que puede evidenciarse en las violaciones de derechos económicos y sociales, que padecen mujeres y hombres venezolanos en su país, por lo que se ven obligados a migrar de forma individual y grupal. Así, centenares de familias se han desplazado hacia zonas que consideran más seguras y que pueden brindarles la calidad de vida necesaria.

Los migrantes venezolanos que llegan al país presentan características particulares; no se tratan de los mismos que migraron en épocas pasadas. Koechlin (2018) señala que a partir de 2015 se produce una cuarta ola de migrantes venezolanos que ingresan al Perú. Estos se caracterizan por presentar una alta necesidad de trabajo y, en su mayoría, ser profesionales. Según una investigación realizada en 2019 por el Banco Mundial, «la población venezolana que ha llegado al Perú es principalmente joven (el $42 \%$ tiene entre 18 y 29 años), proviene mayoritariamente de zonas urbanas y es altamente calificada» (párr. 19). A ello se añade el hecho de que se insertan en el marco de la PEA. Sin embargo, esta necesidad de trabajar, su nivel de pobreza y, en una gran mayoría, su estado de irregularidad en el Perú hace que accedan a trabajos informales y que sean víctimas de discriminación y racismo.

Ahora bien, respecto a los casos de xenofobia que se han experimentado al interior del territorio peruano hacia los migrantes venezolanos, se establecen diferentes perspectivas sobre sus posibles causas. Por ejemplo, Loayza (2020) considera que este rechazo irracional hacia lo que es diferente a lo nacional radica en un estereotipo sexual, trabajadores sexuales, que se percibe del migrante venezolano en el imaginario de la población peruana, así como la inseguridad que inspira, todo lo cual se apoya en la intensificación de estigmas construidos hacia ellos en los medios de comunicación. Guadalupe (2019) añade que el desplazamiento laboral es un factor muy presente en la sociedad peruana y causa actitudes y discursos xenófobos hacia los migrantes venezolanos. Estos discursos xenófobos han sido tratados en el marco político por parte de autoridades peruanas y venezolanas. Este último sector ha rechazado cualquier tipo de discriminación al venezolano en condición de migrante, aunque también han reconocido que no se trata de una xenofobia generalizada, sino de ciertos sectores peruanos que tienen esta actitud (BBC News Mundo, 2019). Además, como se trató anteriormente, el estado de irregularidad es muy recurrente en los migrantes venezolanos que llegan al Perú, ya que se insertan en un sistema de explotación laboral casi forzosa (Lovón et al., 2021). Según Guadalupe (2019), una gran mayoría de ellos incursiona en el ámbito ambulatorio como principal actividad económica; es decir, 
trabajan de manera informal en los espacios públicos. Las investigaciones demuestran que en los sectores de las calles y los espacios públicos se evidencia la mayor cantidad de actitudes negativas hacia los migrantes venezolanos en el Perú, y que son los medios de comunicación en donde se promueven estos actos de discriminación y xenofobia (Sánchez, 2021).

\section{Metodología}

El enfoque de la investigación es de carácter cualitativo. Según Hernández-Sampieri y Mendoza (2018), este enfoque permite observar la manera en que los individuos perciben los fenómenos en su entorno profundizando e interpretando su significado. La unidad de análisis son los repertorios interpretativos que se evidenciaron en los tuits de los usurarios peruanos en la red social Twitter. Para la selección de los tuits se tomaron en consideración los siguientes criterios: aquellos que representan y evidencian el rechazo hacia el comerciante informal venezolano, aquellos que hayan sido elaborados por usuarios peruanos, y aquellos que explicitan las palabras comerciantes informales, ambulantes y venezolano. Los tuits abarcan desde 2018 hasta inicios de 2021. Durante el periodo señalado, en el Perú se produjo un impacto significativo de migración venezolana, pues, según datos proporcionados por la Acnur, se establecieron entre 500000 y 1000000 de migrantes. Además, se desarrollaron las elecciones congresales extraordinarias, las elecciones presidenciales y la pandemia generada por la covid-19, eventos que se relacionan con las promesas migratorias, promesas laborales y el conflicto por el uso de los espacios públicos. Por último, los tuits seleccionados mantienen la ortografía y la redacción sin alteraciones, ya que consideramos que manifiestan la manera en que los usuarios pretenden expresar su sentir y puntos de vista.

Por otro lado, el estudio se sitúa en el marco de las investigaciones en los espacios virtuales; específicamente, las redes sociales. Los avances tecnológicos han posibilitado que estos medios se acerquen a una gran cantidad de masa poblacional, en consecuencia, los medios de comunicación virtual se han convertido en un portal masivo en el cual se debaten y se discuten temas de diversas índoles. Entre los medios de comunicación virtual encontramos a las redes sociales. Celaya (2008) señala que las redes sociales son espacios en Internet donde los usuarios publican y comparten información. En esta línea, Hütt (2012) agrega que las redes sociales facilitan la interacción entre personas; sin embargo, esta interacción suele darse desde el anonimato parcial o total de los usuarios.

Para esta investigación, tomando en cuenta lo señalado sobre el corpus, nos enfocamos en la red social Twitter. Esta red social acoge una gran cantidad de usuarios en el mundo y su contenido se actualiza constantemente; 
en consecuencia, se generan reacciones y comentarios de manera inmediata. Por estas razones, Twitter es un espacio donde los usuarios pueden debatir e intercambiar opiniones libremente en tiempo real. Los temas que se debaten abarcan cuestiones con diversas temáticas: economía, salud, tecnología, política, nacionalidad, migración, etc. Por otro lado, Twitter también se caracteriza por la libertad y los espacios abiertos. Usualmente, los usuarios, tomando en cuenta lo señalado previamente, elaboran tuits que contienen sentimientos negativos, rechazo, violencia, etc. Por ello, estudiar este tipo de discursos nos permite conocer y acceder al pensamiento individual en una determinada comunidad al momento de representar o emitir juicios de valor hacia otro grupo de personas.

Por último, el método de análisis utilizado es el análisis del discurso; específicamente, los repertorios interpretativos propuestos en la psicología discursiva (Potter y Wetherell, 1987; Wetherell y Potter, 1996). Este análisis nos permite encontrar patrones regulares que se relacionan con el léxico, las metáforas, las figuras retóricas y otros procesos cognitivos a través de los cuales los hablantes construyen y elaboran representación e imaginarios respecto a un determinado grupo social; en este caso, sobre los comerciantes informales venezolanos.

\section{Análisis}

En el presente apartado se analizan los tuits que cumplieron los criterios para la selección de la muestra; es decir, en los cuales se evidencia el rechazo de los usuarios peruanos hacia los comerciantes informales venezolanos. Hemos organizado el apartado en subtítulos que explicitan cada uno de los repertorios interpretativos encontrados que se han construido a través de patrones regulares: i) comerciantes informales venezolanos como invasores de los espacios públicos; ii) criminalización de los comerciantes informales venezolanos; iii) el nacionalismo y la pertenencia.

\section{Comerciantes informales venezolanos como invasores de los espacios públicos}

El primer repertorio interpretativo que presentamos es los comerciantes informales venezolanos como invasores y dueños de los espacios públicos. En este repertorio se deben tener en cuenta las experiencias personales (Wetherell y Potter, 1992) de los usuarios y los factores sociales y culturales (Bassaletti-Contreras, 2013) que se involucran. Además, también es importante agregar que en los espacios públicos se suelen evidenciarse la mayor cantidad de actitudes negativas hacia los migrantes venezolanos en el Perú (Sánchez, 2021). Observemos a continuación el siguiente tuit: 
(1) Soy de Perú, en las calles ya no se puede con los comerciantes ambulantes informales venezolanos que venden amburguezas [...]

https://twitter.com/Elbesodeale/status/1178397903913660416

El conflicto por los espacios públicos es una constante en este apartado. En (1) observamos que el usuario inicia el tuit explicitando su nacionalidad: "Soy de Perú»; a partir de ello, explica que, basado en su experiencia diaria, no pueden transitar libremente en las calles, debido a que los comerciantes informales venezolanos ocupan estos espacios públicos al momento de instalar sus negocios clandestinos; en este caso, la venta de hamburguesas. La ocupación de los espacios públicos hace que los usuarios acumulen un conjunto de características e ideas que construyen alrededor del comerciante informal venezolano y, de esta manera, es percibido con la metáfora del invasor. Observemos el siguiente tuit:

(2) [...] se apropian de calles como ambulantes [...]

Encima llaman xenófobos a Peruanos q exigen a gob más control en frontera

https://twitter.com/Mjv33Monica/status/1185896030006415361

En (2) destacamos el uso del verbo apropiar por parte del usuario para fortalecer la metáfora del invasor. Esta apropiación está basada en la experiencia, por medio de la observación del cibernauta y en el estigma que generan los medios de comunicación hacia el migrante venezolano (Loayza, 2020). De esta manera, el usuario expresa su rechazo señalando que los comerciantes informales venezolanos se hacen dueños, ocupan y ponen bajo su poder las calles y espacios públicos. Más adelante, el usuario evidencia una posible justificación a través de la aplicación de este repertorio interpretativo; es decir, rechazar los actos de apropiación de los migrantes no lo convierten a él, ni a los otros peruanos que lo rechazan, en xenófobos. Esta justificación se entrelaza con la idea que los repertorios pueden justificar y construir imágenes y explicaciones racistas (Wetherell y Potter, 1996).

(3) En Perú:

Vendedores ambulantes venezolanos: *venden donde no deben* Municipalidad: *los sacan porque está prohibido*

Vendedores: *se excusan de que tienen derechos, tildan a todos de xenófobos, escupen groserías y maldicen al país*

https://twitter.com/noheliaortiz/status/1231040689825370113

En (3) observamos que el usuario evidencia una secuencia sobre las actividades diarias de los ambulantes venezolanos y su relación conflictiva 
con las municipalidades. A través de la construcción «venden donde no deben», se evidencia el conflicto con los espacios públicos y, en consecuencia, nuevamente, se construye el discurso del comerciante informal venezolano con la metáfora del invasor de los espacios. La construcción del comerciante informal venezolano como invasor genera consecuencias en la percepción de la población respecto a los extranjeros (Roldán, 2019). De igual manera que en los casos anteriormente presentados, existe influencia de la experiencia personal y de la representación de migrantes a través de los medios de comunicación para la construcción de una imagen que los usuarios suelen emplear constantemente. Más adelante, en el tuit el usuario agrega que los comerciantes informales venezolanos se victimizan excusándose en sus derechos. Por último, la construcción negativa de los comerciantes informales continúa cuando el usuario utiliza las siguientes construcciones: «escupen groserías» $\mathrm{y}$ «maldicen al país». La construcción de estas conductas inaceptables no solo sirve para mostrar rechazo, sino una manera de categorizar al comerciante informal venezolano como maleducado.

(4) @willaxtv Jaime .Nadie votará por Salaverry .tu no vives en Peru . Anda al Mercado Central se han apoderado de los espacios de los ambulantes Peruanos. Los Venezolanos les pegan son malos.

https://twitter.com/aristotelesgc/status/1370598793759051778

Finalmente, el último tuit de esta sección está contextualizado en el año de las elecciones presidenciales en el Perú (2021). Durante este periodo, de igual manera que en las elecciones congresales extraordinarias y en las elecciones municipales, se generaron conflictos y debates sobre la problemática de la migración venezolana y sus consecuencias. Entre ellas, se evidencia el conflicto de los espacios públicos que, como señala el usuario, han sido apropiados por los ambulantes venezolanos. Respecto al uso del verbo apoderar, en conjunto con apropiarse y adueñarse, conforman un campo semántico que comparte el rasgo común de invasor. De esta manera, observamos que la construcción del comerciante informal venezolano continúa relacionándose con la metáfora del invasor. Finalmente, el usuario fortalece la construcción negativa de los venezolanos cuando los relaciona con acciones violentas hacia los peruanos («les pegan son malos»).

\section{La criminalización de los comerciantes informales venezolanos}

El segundo repertorio interpretativo que presentamos es la criminalización de los comerciantes informales venezolanos. El repertorio se ha construido por medio de patrones regulares que se explicitan en los discursos 
de los usuarios peruanos a través del léxico y la generalización. El repertorio está influenciado por las experiencias personales (Wetherell y Potter, 1992), factores sociales y culturales (Bassaletti-Contreras, 2013) y el estigma generado por los medios de comunicación (Loayza, 2020). Esto genera que los usuarios emitan discursos xenófobos y racistas y, en consecuencia, caractericen a los comerciantes venezolanos como delincuentes. Observemos a continuación el siguiente tuit:

(5) Esos venezolanos detenidos estaban delinquiendo, asaltar centros comerciales, cortar gente en padacitos y lad ventas ambulantes, son delitos en Perú. Si no van a trabajar no vayan, la buhonería no es trabajo, es delito

https://twitter.com/Baco1963/status/1177658617350234112

En (5) el usuario caracteriza a los venezolanos como criminales cuando los relaciona con actos delictivos basado en la experiencia personal a través de las siguientes construcciones: «estaban delinquiendo», «asaltar centros comerciales» $y$ «cortar gente en $\mathrm{p}[\mathrm{e}]$ dacitos». Todos estos eventos señalados previamente también se relacionan con reportes de los medios de comunicación donde los migrantes venezolanos están involucrados. Por ejemplo, el caso del peruano que fue descuartizado por un adolescente venezolano. Al respecto, cabe señalar que este hecho conmocionó a todo el país al ver las imágenes y confesiones escalofriantes del victimario, tanto por la matanza contra un compatriota venezolano y su acompañante peruano (El Comercio, 2019b). El adolescente, con sus cómplices, lanzó un video que se difundió en la televisión y se viralizó las redes sociales, donde mostraban el cráneo decapitado del cuerpo de una de las víctimas (Venezolanos en Perú, 2021). Ello generó que los peruanos rechacen y teman a la migración venezolana. La confianza se perdió mucho con este caso. Luego, el usuario generaliza y agrupa todas las acciones en conjunto con la venta ambulatoria como delitos. Más adelante, el usuario explicita y señala que la «buhonería» —uno de los empleos informales más utilizados por parte de los comerciantes informales venezolanos - no es un trabajo, sino un delito. Se evidencia la construcción de una imagen delincuencial de los comerciantes informales venezolanos a partir de la ya señalada experiencia personal e influencia de los medios. Por ejemplo, observemos el siguiente tuit:

(6) [...] ya no se puede con los comerciantes ambulantes informales venezolanos [...] si les dices algo sacan cuchillos para amedrentar, Ante eso no se puede hacer nada ni grabarlos.

https://twitter.com/Elbesodeale/status/1178397903913660416 
En este caso, observamos que el usuario peruano expresa temor hacia la actitud criminal que se construye sobre los comerciantes informales venezolanos cuando señala que «sacan cuchillos para amedrentar». Asimismo, agrega la siguiente construcción: «no se puede hacer nada», que es otro discurso utilizado constantemente cuando los usuarios son víctimas de actos delictivos. Además, el temor al delincuente se ejemplifica con la expresión de la cláusula negativa «no se puede hacer nada ni grabarlos». El rechazo hacia la imagen criminalizada del comerciante informal venezolano continúa relacionándose con eventos previamente ocurridos. Observemos el siguiente tuit:

(7) En Perú hartos delincuentes Venezolanos:

[...] se apropian de calles como ambulantes [...]

-no respetan a los policías, -implicados en descuartizamientos,robos [...]

https://twitter.com/Mjv33Monica/status/1185896030006415361

El usuario utiliza el adjetivo harto para expresar la gran cantidad de «delincuentes venezolanos» y cómo estos se han apropiado de las calles. Nuevamente, se los continúa relacionando con hechos previamente ocurridos; en este caso, a los delitos de descuartizamiento - evento difundido por los medios de comunicación y por la sociedad peruana en general en 2019- y los robos para alimentar la carga semántica negativa a su imagen. La caracterización y la representación de la imagen criminalizada de los comerciantes informales venezolanos también se da por medio del uso de adjetivos como se observa a continuación:

(8) [...] llegan enfermos sin familia destino solo ser ambulantes creando suciedad dejando enfermedades en mi Pais Peru hay demasiado sicarios delincuentes vagos flojos sucios venezolanos.

https://twitter.com/Gleap9/status/1323486441180200960

Con una imagen previamente construida, el usuario selecciona los siguientes adjetivos para nombrar a los comerciantes informales venezolanos: delincuentes, vagos, flojos y sucios. De esta manera, evidenciamos que existe una interrelación entre el ambulante y la delincuencia. Más adelante, el usuario agrega que el destino de los migrantes es «solo ser ambulantes» y, en consecuencia, su llegada generaría suciedad y dejarían enfermedades, elementos explícitamente relacionados con la tragedia. De esta manera, tomando en cuenta su imagen caracterizada negativamente, el comerciante informal venezolano es comparado con el delincuente $y$, por lo tanto, generalizado como tal. 


\section{Nacionalismo-pertenencia}

El tercer repertorio interpretativo que presentamos es el nacionalismo-pertenencia. Para este repertorio es importante tener en cuenta el sentimiento de pertenencia de los usuarios basado en la victimización y el rechazo hacia los otros - comerciantes y migrantes venezolanos-, que a su vez está basado en prejuicios alimentados por el racismo y la xenofobia. En esta línea, Guadalupe (2019) señala que el desplazamiento laboral es un factor muy presente en la sociedad peruana y causa actitudes y discursos xenófobos. Tomando en cuenta lo señalado previamente, existe un rechazo hacia la nacionalidad venezolana asentada en un sentimiento de pertenencia. Observamos a continuación el siguiente tuit:

(9) Hace rato. Están desplazando [el comerciante informal venezolano] escandalosamente a peruanos. Que es la patria entonces?

https://twitter.com/OcampoYlder/status/1125601776781148160

Tomando en cuenta lo señalado por Guadalupe (2019), el usuario evidencia su rechazo hacia los comerciantes informales venezolanos en su tuit cuando responde a la noticia de la cuenta en Twitter del diario peruano Correo, el cual señalaba en ese entonces que la «Ministra de Trabajo asegura que presencia de venezolanos afecta el mercado laboral en Perú»; a partir de ello, en la sección comentarios se generó el debate sobre los comerciantes informales venezolanos. El usuario justifica su rechazo debido al desplazamiento previamente señalado e intensifica su mensaje con el uso del adverbio escandalosamente. Finaliza el tuit con la siguiente interrogante: «[i]Que es la patria entonces?». El usuario menciona, a través de la formulación de una pregunta retórica, a la patria en su discurso para resaltar la importancia de los peruanos y estos puedan ser percibidos como víctimas ante un posible «abandono» por parte del Estado y su apoyo a los otros (venezolanos).

(10) SON O SE HACEN? SE LES ADVIRTIÓ EN REDES AL FANFARRÓN Y DEMAGOGO VIZCARRA QUE PONGA ORDEN A LA INMIGRACION INDISCRIMINADA DE VENECOS QUE LE QUITA EL EMPLEO A LA GENTE DE EXTREMA POBREZA EN EL PERÚ, AHORA CUANDO YA NO HAY REMEDIO RECIÉN SE DAN CUENTA

https://twitter.com/Soyderecho1000/status/1125776731422580736

En el tuit (10) nuevamente observamos la generalización de atribuir al Estado el problema migratorio y, en consecuencia, laboral. El usuario utiliza, de igual manera que el usuario anterior, el discurso del desplazamiento laboral del peruano por parte del venezolano que a su vez se vincula con la victimización: «VENECOS QUE LE QUITA EL EMPLEO A LA GENTE». Además, se evidencia el uso del vocablo veneco, que, en esta 
ocasión, contiene carga despectiva cuando se nombra a los migrantes venezolanos. Finalmente, en este tuit resaltamos el uso de las mayúsculas por parte del usuario durante todo el mensaje, con la finalidad de enfatizar su mensaje; de esta manera, busca que su texto sea leído en medio del registro de otros tuits.

(11) El Perú se ha convertido en la chacra de la crisis Venezolana.

700 mil Venezolanos oficialmente, han desplazado el trabajo informal, de Miles de peruanos que se la buscaban en paraderos y de vendedores en los buses.

Han desplazado al sector más pobre del Perú. El Perú retrocede

https://twitter.com/AlfonsoTT/status/1113269113378549763

El discurso del desplazamiento laboral se sigue explicitando y continúa relacionándose con la victimización por parte de los peruanos. El usuario inicia el tuit señalando que «el Perú se ha convertido en la chacra de la crisis venezolana»; de esta manera, hace referencia a que los migrantes venezolanos se han apoderado de los espacios peruanos, como se señaló en el primer repertorio, y en ellos realizan actividades para su sobrevivencia. Más adelante, el usuario agrega que los comerciantes informales venezolanos «han desplazado el trabajo informal» de los peruanos que trabajaban informalmente. Este discurso de desplazamiento incluye una cuantificación sin fuente, pero que revela una hipérbole discursiva. Además, también advertimos un discurso que evidencia la preferencia del informal peruano sobre el informal venezolano; esto es, el rechazo tiene una carga xenófoba: «nuestros informales» contra los otros informales (comerciantes informales venezolanos). El usuario finaliza el tuit con el tema central de su discurso: desplazamiento y victimización; en esta línea, los imaginarios previamente señalados muestran y sostienen el comportamiento de rechazo.

(12) Ya sabemos que son de nacionalidad \#venezolana, quienes quitan más que aportar. Todo \#venezolano en el Perú informal debe ser botado del país, basta ya de darles prorrogará anualmente, ahora estamos pagando los platos rotos.

\#NoMásVenezolanos

\#NoEsXenofobia

https://twitter.com/GeorgioMonreal/status/1257759386208022533

Por último, en el tuit (12) el usuario nombra directamente a los venezolanos con el uso de un hashtag (\#venezolana) y se refiere a ellos como los que obstaculizan el desarrollo («quitan más que aportar»); de esta manera, construyen una imagen negativa de ellos, lo cual ha sido una tendencia 
en los tuits analizados. Asimismo, el usuario considera que los informales deben ser erradicados, pues percibe que los peruanos son perjudicados por el mal accionar de los venezolanos, una imagen negativa que se ha construido constantemente por los usuarios peruanos. Este discurso de cansancio y hartazgo hacia el ambulante venezolano se explicita con la construcción «basta ya» $y$, en consecuencia, se construye el rechazo hacia la nacionalidad de los migrantes. Además, considera que los peruanos son los principales afectados ante la llegada de los migrantes cuando el usuario señala que «ahora estamos pagando los platos rotos». Por último, en este tuit, destacamos los hashtags que utiliza el autor: \#NoMásVenezolanos y \#NoEsXenofobia. En el primer hashtag se evidencia un rechazo explícito y directo; por otro lado, en el segundo hashtag el usuario pretende justificar sus expresiones racistas cuando señala que no se trata de xenofobia.

\section{Conclusiones y reflexiones}

En el análisis contemplamos que los repertorios interpretativos configuran la ideología del migrante venezolano como problema laboral, social y económico. Desde la psicología social, se ve que los repertorios, que pueden equiparse con la noción de representaciones desde la sociología, configuran formas de creer y pensar al otro, que terminan por asimilarse y aprenderse en una sociedad por su propalación entre los grupos sociales. Las mujeres y hombres venezolanos son vistos desde la negatividad, por hechos sucedidos y por la manera en que son percibidos.

La generalización de estereotipos afecta los modos en que los ciudadanos peruanos los ven. Dichos prejuicios se extienden en la sociedad, la educación, la Internet e incluso la literatura (Arámbulo, 2018). Particularmente, se ha visto que el rechazo hacia los comerciantes informales venezolanos, por parte de los usuarios peruanos en la red social Twitter, se construye discursivamente a través de tres repertorios interpretativos: los comerciantes informales como invasores de los espacios públicos, la criminalización de los comerciantes informales venezolanos y el nacionalismo-pertenencia.

Cada repertorio interpretativo se construye a través de patrones regulares. En el caso de la invasión de los espacios públicos, el rechazo se genera a partir de la experiencia de los usuarios que no pueden trasladarse libremente en las calles ante la apropiación de los espacios por parte de los comerciantes informales venezolanos; en consecuencia, son percibidos y construidos por medio de la metáfora de invasores. Al respecto, cabe recordar el concepto de estigma que Goffman (1963) introdujo para sostener que socialmente se crean atributos, señales y marcas, que 
desacreditan o deshonran a sus poseedores, por lo que las personas se convierten en sujetos «manchados». Tales estigmas generan emociones negativas como el odio y el miedo, y la exclusión de personas de la vida social.

En el caso de la criminalización, este repertorio se expresa mediante la selección léxica y el uso de adjetivos que caracterizan negativamente a los venezolanos como delincuentes basados en la experiencia personal. Es importante tomar en consideración la representación de los informales venezolanos por parte de los medios de comunicación peruanos en sus noticias.

En el caso del nacionalismo-pertenencia, el patrón recurrente es la victimización ante un «abandono» por parte del Estado hacia los propios peruanos y por otorgar facilidades a los otros (venezolanos). Además, es necesario agregar que este rechazo a lo venezolano y defensa de lo nacional descansa en el discurso del desplazamiento de los informales y trabajadores peruanos; en consecuencia, se genera el rechazo a la nacionalidad de los migrantes. Esto evidencia una preferencia por «nuestros formales» y genera hashtags como \#NoMásVenezolanos en las redes sociales.

Asimismo, hemos observado que los patrones en cuestión se relacionan con lo señalado por Wetherell y Potter (1992), respecto a que los repertorios se constituyen a partir de experiencias personales y colectivas, y que, además, están determinados por factores sociales y culturales (Bassaletti-Contreras, 2013). Los cibernautas han compartido sus reacciones de manera individual, y aunque no hemos estudiados los retuiteos, las coincidencias y similitudes discursivas sostienen formas de pensar común que se propalan en la red social.

Van Dijk (2000) ha señalado que los discursos son socialmente compartidos, porque se repiten, se reproducen y se legitiman. También es importante agregar que los patrones están bajo la influencia de los estigmas generados en los medios de comunicación hacia los venezolanos (Loayza, 2020) cuando transmiten o comunican eventos donde los comerciantes informales venezolanos se encuentran involucrados; por ejemplo, asaltos, asesinatos, conflictos contra con los municipales, etc. Estos recursos que se comparten en el imaginario de la sociedad peruana son evidenciados en las redes sociales; en este caso, la red social Twitter, y generan consecuencias ideológicas (Sánchez, 2015). De esta manera, se ha construido una identidad xenofóbica y racista por parte de un grupo de usuarios peruanos. Cabe señalar que los venezolanos en el Perú atraviesan una doble discriminación, por el hecho de ser migrantes y proceder de sectores vulnerables, o ser percibidos como tales, a pesar de las profesiones y educación 
que pudieran haber alcanzado en su país. En el Perú, el venezolano está siendo concebido como un sujeto social, o mejor dicho objeto social, por debajo de los peruanos pobres. A estas condiciones se somete como producto de la emigración forzada en que se halla.

A modo de reflexión, se considera importante señalar lo siguiente en torno a los aspectos y las condiciones laborales, respecto a los comerciantes informales venezolanos, y el migrante venezolano en general: es importante que las políticas migratorias en el Perú promuevan la inserción laboral de los migrantes, por las capacidades que presentan (Valdiglesias, 2018, p. 83). En esta línea, también se deben garantizar el bienestar y el acceso a los sectores de salud, educación y otros, ya que, según Castro (2019), el Perú no promueve ni facilita la integración de la población migrante. Según Mendoza y Miranda (2019) indican que el sector salud sería uno de los ámbitos beneficiados si se regulariza la inserción laboral de los migrantes venezolanos, pues una gran cantidad de ellos son profesionales en este rubro. Asimismo, resaltamos que el sector salud es actualmente el más solicitado, debido al contexto pandémico causado por la covid-19. Por otro lado, más allá del ámbito económico, se deben considerar y tomar en cuenta la aplicación de sus derechos para una mejor calidad de vida. Sin embargo, tampoco se debe ignorar la situación del informal peruano, ya que contribuir en su formalización evitará la construcción de sentimientos e imaginarios de rechazo al migrante. Sobre el punto, con una correcta aplicación de la política migratoria se regularizarían los problemas de discriminación y xenofobia, ya que la sociedad peruana y venezolana serían beneficiadas mutuamente mediante un proceso de integración donde la población venezolana acceda a los servicios de manera formal y la población peruana se beneficiaría de los servicios que proporcione la población migrante. La lucha contra la discriminación y el maltrato migratorio requiere también de pensar en acciones concretas que favorezcan la construcción de repertorios interpretativos positivos, frente a aquellos que abundan en la representación negativa de los migrantes.

\section{Contribución de los autores}

Los autores declaran que han participado en el diseño de la investigación, la recolección y el procesamiento de los datos, y la revisión del manuscrito final.

\section{Fuente de financiamiento}

Este artículo se ha elaborado en el marco del proyecto de investigación E21030371 del Vicerrectorado de Investigación y Posgrado de la Universidad Nacional Mayor de San Marcos (RR 005753-2021-R/UNMSM). 


\section{Conflicto de interés}

Ninguno.

\section{REFERENCIAS BIBLIOGRÁFICAS}

Aceros, J.-C., Cavalcante, M.-T., Domènech, M. (2016). Envejecer en casa con teleasistencia en España. Un análisis del discurso. Ciência \& Saúde Coletiva, 21(8), 2413-2421. http://www.cienciaesaudecoletiva.com.br/ artigos/envejecer-en-casa-con-teleasistencia-en-espana-un-analisis-deldiscurso/16574?id=16574

Alto Comisionado de las Naciones Unidas para los Refugiados, Acnur. (2019). Los flujos de venezolanos continúan constantes, alcanzando ahora la cifra de 3,4 millones. https://bit.ly/2PuQvgb

Arámbulo, C. (2018). El sujeto migrante posmoderno en la literatura-mundo. Desde el Sur, 10(1), 217-230. https://revistas.cientifica.edu.pe/index. $\mathrm{php/desdeelsur/article/view/437}$

Aruj, R. (2008). Causas, consecuencias, efectos e impacto de las migraciones en Latinoamérica. Papeles de Población, 14(55), 95-116. http://www.scielo.org.mx/scielo.php?script=sci_arttext\&pid=S140574252008000100005\&lng=es\&tlng=es.

Banco Mundial, BM. (26 de noviembre de 2019). La migración venezolana puede impulsar la productividad y el crecimiento económico del Perú. https:// www.bancomundial.org/es/news/press-release/2019/11/26/migracionvenezolana-peru

Bassaletti-Contreras, R. (2013). Construyendo realidades: usos de bullying en discursos chilenos. Summa Psicológica UST, 10(1), 9-22. http://pepsic. bvsalud.org/pdf/summa/v10n1/a02.pdf

Berganza, I. y Solórzano, X. (2019). El proceso de integración social de la migración venezolana en el Perú. En C. Blouin (Coord.), Después de la llegada. Realidades de la migración venezolana (pp. 83-101). THEMIS. https:// bit.ly/3vlGfpN

Blouin, C. (13 de junio de 2017). Entrevista a Cécile Blouin: Migración venezolana en Perú. Parthenon.pe. http://www.parthenon.pe/publico/internacional-publico/migracion-venezolana-en-peru-entrevista-a-cecileblouin/

Blouin, C. (2019). Antes de la llegada: migración (forzada) de personas venezolanas. En C. Blouin (Coord.), Después de la llegada. Realidades de la migración venezolana (pp. 13-21). THEMIS. https://bit.ly/3vIGfpN 
Briones-Vozmediano, E., Davó-Blanes, M.-C, García-de la Hera, M., Goicolea, I., y Vives-Cases, C. (2016). Discursos profesionales sobre la violencia del compañero íntimo: implicación en la atención de las mujeres inmigrantes en España. Gaceta Sanitaria, 30(5), 326-332. https://dx.doi.org/10.1016/j. gaceta.2016.04.022

Bruno, S. y Arrúa, E. (2019). En búsqueda de la tranquilidad perdida. La inmigración venezolana reciente en el Área Metropolitana de Asunción. En L. Gandini, F. Lozano y V. Prieto (Coords.), Crisis y migración de población venezolana. Entre la desprotección y seguridad jurídica en Latinoamérica (pp. 285-310). Universidad Nacional Autónoma de México.

Bustamante, M., Díaz, R. y Villareal, P. (2009). Economía informal: Un análisis al comercio ambulante de la región del Maule, Chile. Fórum Empresarial, 14(1), 37-61. https://doi.org/10.33801/fe.v14i1.3407

Calquín, C., Guerra, R., Escobar, R. y Martínez, J. (2020). Repertorios interpretativos de un manual de intervención en la infancia temprana en Chile. Política y Sociedad, 57(1), pp. 197-215. https://revistas.ucm.es/index.php/ POSO/article/view/60255

Camargo, E. (2014). El comercio informal en Colombia: causas y consecuencias. In Vestigium Ire, 5(1), 109-116. http://revistas.ustatunja.edu.co/ index.php/ivestigium/article/view/609

Castro, L. (2019). La migración masiva venezolana en el Perú y las políticas públicas migratorias. [Tesis de grado, Universidad de San Martín de Porres].

Celaya, J. (2008). La empresa en la WEB 2.0. Planeta.

Chicaiza, E. (2017). Análisis del comercio informal y su incidencia a los comerciantes regularizados en la parroquia de Cotocollao, cantón Quito en el año 2015. [Tesis de pregrado, Universidad Central del Ecuador]. http://www. dspace.uce.edu.ec/bitstream/25000/9931/1/T-UCE-0005-048-2017.pdf

Condori, M., Reyna, G., Villavicencio, A., Párraga, C. y Vilcapoma, D. (2020). Éxodo venezolano, inserción laboral y discriminación social en la ciudad de Huancayo, Perú. Espacios, 41(27), 72-83. https://bit.ly/3yQzHRH

Crisis en Venezuela: cuán cierto es que hay una ola de xenofobia hacia los venezolanos en Perú (2 de octubre de 2019). BBC News Mundo.

Cruz, M. (2015). Causas del crecimiento del comercio informal y semiformal en la ciudad de La Paz y su incidencia en la creación de empleos directos e indirectos. [Tesis de grado, Universidad Mayor San Andrés]. https:// repositorio.umsa.bo/handle/123456789/6137

De Soto, H. (1989). The other path. The invisible revolution in the Third World. HarperCollins. 
Edley, N. (2001). Analysing masculinity: Interpretative repertories, ideological dilemmas and subject positions. En M. Wetherell, S. Taylor y S. Yates (Eds.). Discourse as Data (pp. 189-228). Sage. http://www2.clarku. edu/ mbamberg/class\%20material/107/Analysing\%20Masculinity.pdf

El Comercio. (12 de junio de 2019a). Urresti sobre agresión entre serenos y ambulantes: «Hubo exceso, pero fue producto de la adrenalina». El Comercio. https://bit.ly/337ZEOR

El Comercio (30 de septiembre de 2019b). La confesión del adolescente venezolano que descuartizó a dos jóvenes en el hospedaje. https://elcomercio.pe/lima/policiales/la-confesion-del-adolescente-venezolanoque-descuartizo-a-dos-jovenes-en-el-hospedaje-noticia/

Fernández, J. (2009). Aprendiendo a escribir juntos: Multimodalidad, conocimiento y discurso. Comité Regional Norte de Cooperación con la Unesco, A. C. y la Universidad Autónoma de Nuevo León. https://repositorio.tec. $\mathrm{mx} / \mathrm{handle} / 11285 / 577648$

Fuentes, L. (2015). Construcción discursiva de la experiencia anoréxica: un acercamiento desde la evaluación en el lenguaje. [Trabajo para optar por el título de Magister Scientiae en Lingüística, Universidad de Los Andes. http://www.saber.ula.ve/bitstream/handle/123456789/40682/Tesis\%20 Fuentes.pdf?sequence $=1$ \&isAllowed $=y$

Goffman, E. (1963). Estigma: la identidad deteriorada. Amorrortu Editores.

Gómez, J. (2010). La migración internacional: teorías y enfoques, una mirada actual. Semestre Académico, 13(26), 81-100. http://www.scielo.org.co/ scielo.php?script=sci_arttext\&pid=S0120-63462010000100005

Guadalupe, E. (2019). La comunicación para el desarrollo en la promoción de la integración sociocultural de la población nacional y los migrantes y refugiados de Venezuela: el festival «TUMBEmos la xenofobia». [Tesis de licenciatura, Pontificia Universidad Católica del Perú]. http://tesis.pucp.edu.pe/ repositorio/handle/20.500.12404/3/discover

Hütt, H. (2012). Las redes sociales: una nueva herramienta de difusión social. Reflexiones, 91(2), 121-128. https://revistas.ucr.ac.cr/index.php/reflexiones/article/view/1513

Koechlin, J. (16 de abril de 2018). «La migración venezolana se da por causas económicas, de violencia social y política». Antonio Ruiz de Montoya [Entrevistas]. https://www.uarm.edu.pe/Noticias/entrevistas/migracionvenezolana-se-da-por-causas-economicas-violencia-social-politica\#.YLqdRbVKjIW

La República. (24 de noviembre de 2020). Mesa Redonda: varios heridos por enfrentamiento entre ambulantes y fiscalizadores. La República. https://bit.ly/3e8TFQb 
Loayza, N. (2007). The causes and consequences of informality in Peru. Banco Central de Reserva del Perú, Working Paper 18. https://www.bcrp. gob.pe/en/publications/working-papers/wp-2007-18-the-causes-andconsequences-of-informality-in-peru.html

Loayza, J. (2020). Inmigración venezolana y estigmatización laboral en el Perú. Investigaciones Sociales, 23(43), 179-192. http://dx.doi.org/10.15381/ is.v23i43.18492

Lovón, M.-A., García, A.-M., Yogui, D., Moreno, D. y Reyna, B. (2021). La migración venezolana en el Perú: el discurso de la explotación laboral. Lengua y Sociedad, 20(1), 189-220. http://revista.letras.unmsm.edu.pe/index. $\mathrm{php} / \mathrm{ls} /$ article/view/2209

Mendoza, W. y Miranda, J. J. (2019). La inmigración venezolana en el Perú: desafíos y oportunidades desde la perspectiva de la salud. Revista Peruana de Medicina Experimental y Salud Publica, 36(3), 497-503. https://dx.doi. org/10.17843/rpmesp.2019.363.4729

Mesía, Y. (2014). Construcción simbólica de grupos y jerarquías sociales. un estudio comparativo de las ideologías lingüísticas de estudiantes de un colegio estatal y uno particular de Lima. [Tesis de magíster en Lingüística, Pontificia Universidad Católica del Perú]. https://tesis.pucp.edu.pe/repositorio/ handle/20.500.12404/5492

Nolazco, A., Cerrón, E. y Reggiardo, R. (2020). Actores de la economía: Inmigración venezolana, la informalidad y el desempleo en Lima Metropolitana. Espíritu Emprendedor TES, 4(4), 1-17. https://doi.org/10.33970/eetes. v4.n4.2020.211

Pacheco, J. y Palma, M. (2014). El discurso profesional en servicios sociales comunitarios: una aproximación desde la identificación de repertorios interpretativos. Alternativas. Cuadernos de Trabajo Social, 21, pp. 9-28. https://alternativasts.ua.es/article/view/2014-n21-el-discurso-profesional-en-servicios-sociales-comunitarios-una-aproximacion-desde-la-identificacion-de-repertorios-interpretativos

Potter, J. y Wetherell, M. (1987). Discourse and social psychology. Beyond Attitudes and behaviour. Sage.

Quispe, G., Tapia, M., Ayaviri, D., Villa, M., Borja, M. y Lema, M. (2018). Causas del comercio informal y la evasión tributaria en ciudades intermedias. Revista Espacios, 39(41), 4. http://www.revistaespacios.com/ a18v39n41/18394104.html

Roldán, M. (2019). Venezuela, éxodo y crimen. Análisis de la incidencia de la migración en la variación del crimen y la violencia en Medellín 2013-2018. [Tesis para optar por el título de abogado, Universidad EAFIT]. https://repository.eafit.edu.co/handle/10784/13700 
Sánchez, D. (24 de febrero de 2021). ¿Veneco malo, peruano bueno?: La xenofobia contra los migrantes venezolanos en el Perú. Enfoque Derecho. https://www.enfoquederecho.com/2021/02/24/veneco-malo-peruchobueno-la-xenofobia-contra-los-migrantes-venezolanos-en-el-peru/

Sánchez, J. (2015). Repertorios interpretativos de un espacio en transformación: el caso de Armas-Casta Álvarez en Zaragoza. URBS. Revista de Estudios Urbanos y Ciencias Sociales, 5(1), 89-105. http://repositorio.ual.es/ handle/10835/3794

Suárez, D. (2008). Causas y efectos de la migración internacional. Perspectivas, 22, 161-180. https://www.redalyc.org/articulo.oa?id=425942158006

Trome. (25 de octubre de 2019). La Victoria: Violenta pelea entre «jaladores» peruanos y venezolanos termina con saqueos en Gamarra. Trome. https://bit.ly/2QQSQ5J

Valdiglesias, J. (2019). Efectos de corto plazo de la inmigración venezolana en el Perú. Pensamiento Crítico, 23(2), 73-96. https://doi.org/10.15381/ pc.v23i2.15805

Van Dijk, T. (2000). El discurso como interacción social. Gedisa Editorial.

Venezolanos en Perú. (18 de junio de 2021). Gobierno peruano accede a solicitud de extradición de ciudadana venezolana implicada en doble descuartizamiento en San Martín de Porres. https://venezolanosenperu. com.pe/gobierno-peruano-accede-a-solicitud-de-extradicion-de-ciudadana-venezolana-implicada-en-doble-descuartizamiento-en-san-martinde-porres/

Wetherell, M. (1998). Positioning and interpretative repertoires: conversation analysis and post-structuralism in dialogue. Discourse and Society, 9(3), 431-456. https://journals.sagepub.com/doi/10.1177/0957926598009 003005

Wetherell, M. y Potter, J. (1992). Mapping the language of racism. Discourse and the legitimation of explotation. Harvester Wheatsheaf.

Wetherell, M. y Potter, J. (1996). El análisis del discurso y la identificación de los repertorios interpretativos. Á. J. Gordo López y J. L. Linaza Iglesias (Coord.). Psicologías, discursos y poder (pp. 63-78). Visor. https://dialnet. unirioja.es/servlet/articulo?codigo $=5180991$

Zavala, V. (2016). Ideologías sobre el quechua desde el poder: una aproximación discursiva. Signo y Seña, 29, 207-234. http://revistas.filo.uba.ar/ index.php/sys/index 